\title{
El enfoque histórico en el análisis de falsos cognados en español y portugués. A propósito del par "suceso / sucesso"
}

\author{
José Alberto Miranda Poza ${ }^{1}$
}

\section{Resumen}

En algunos de los estudios publicados sobre falsos cognados: Lado (1973), Leiva (1994), Bugueño Miranda (1998) o Durão (2002; 2004; 2005), el enfoque se limita a la lingüística aplicada, en su vertiente comunicativa o interaccionista. Sus autores se esfuerzan por explicar cuáles son las consecuencias, en el habla, de su presencia y su incidencia en la interlengua. En este artículo, se destaca la importancia que adquiere para el profesor de lenguas una comprensión totalizadora del problema, que exigirá un análisis de la historia de la lengua partiendo de la etimología de los vocablos enfrentados. Así, se llegará al porqué del fenómeno, no reducido a una mera descripción, sino mostrando el curso de cada vocablo en las respectivas lenguas, su forma y su sentido. Finalmente, se estudia el par suceso / sucesso, que nos conducirá a otras lenguas románicas, demostrando la dimensión global del abordaje propuesto.

Palabras clave: falsos cognados; historia de la lengua; interfaces portugués-español.

\begin{abstract}
In some of the published studies on false cognates: Lado (1973), Leiva (1994), Bugueño Miranda (1998) or Durão (2002; 2004; 2005), the focus is limited to Applied Linguistics in its Communicative or Interactionist approaches. Its authors strive to explain what the consequences of its occurrence in speech are and its impact on interlanguage. This article stresses the importance a holistic understanding of the problem has for the language teacher, which will require an analysis of the history of language starting from the etymology of the words at issue. Thus, it will get down to the origin of the phenomenon, not reduced to a mere description, but showing the path of each word in each language, their form and their meaning. Finally, we study the pair suceso/successo which will lead us to other Romance languages, which shows the global dimension of the proposed approach.
\end{abstract}

Keywords: false cognates; history of language; Portuguese-Spanish interfaces.

\section{Introducción: presentación del problema}

Son múltiples los estudios que tratan del tema de los llamados falsos cognados o, como calco de la expresión francesa faux amis, acuñada por Koessler y Derocquigny (1928) con referencia a las lenguas francesa e inglesa, falsos amigos, entre dos lenguas formalmente tan próximas y genéticamente emparentadas como español y portugués. Baste mencionar, a modo de ilustración, los de Beato y Durão (2001), Bugueño Miranda (1998), Camorlinga Alcaraz (2005), Durão (2002; 2004; 2005), Feijóo Hoyos y Hoyos Andrade (1992), Lado (1973), Leiva (1994), Sabino (2006), Schmitz (2001) o

\footnotetext{
${ }^{1}$ Profesor del Programa de Posgrado en Letras y profesor Del Departamento de Letras de la UFPE, Recife - PE (Brasil). E-mail: ampoza@ globo.com

Revista Leitura V.2 no 56 - jul/dez 2015 - Número regular - Autor/a: José Alberto Miranda Poza - p. $133-152$.
} 
Werner (1997; 2006), que abordan, desde perspectivas y objetivos diversos este mismo tema.

En uno de estos trabajos, Bugueño Miranda (1998) incidía en un aspecto esencial y que, tal vez, no despertó el interés de la crítica como a nuestro entender hubiera merecido, la perspectiva histórica, a pesar de que el objetivo del citado investigador se centrase más en destacar las diferencias de uso, consecuencia de la acción del tiempo, y no en explicar cómo el origen común de ambas lenguas nos llevaría a preguntarnos si, en efecto, esas supuestas semejanzas que se dan entre palabras próximas lo son realmente, es decir, si su significado respectivo viene a ser el mismo, por más que su sentido, por motivos achacables ya sea a fenómenos onomasiológicos, ya a semasiológicos, haya provocado designaciones particulares y distintas en el uso, esto es, en la aplicación específica que a cada término se le ha venido a asignar en cada lengua en una determinada época.

Lo mismo podríamos aducir a propósito del trabajo de Leiva (1994), que, si bien en sus primeras páginas se detiene en breves consideraciones históricas, lo hace como marco generalizador, para poco después apartarse de este propósito para centrarse en la justificación del concepto de transferencia en el aprendizaje de lenguas segundas como factor desencadenante de la interlengua, en especial en el caso del español y el portugués, llevando así su estudio al ámbito del habla y de la lingüística aplicada.

Para nosotros, si consideramos la formación que debe suponérsele al profesor de lengua extranjera, de modo muy señalado cuando en la interacción profesor-alumno flotan en el ambiente, entremezclados, portugués y español, explicaciones y análisis de índole etimológica se hacen inexcusables no ya para la consecución del éxito en el proceso de enseñanza-aprendizaje de la lengua meta, sino también a la hora de entender, comprender y asimilar en su justa medida la verdadera dimensión del problema en cuestión. Más allá de la obviedad -sentidos diferentes en dos lenguas enfrentadas para palabras formalmente próximas o semejantes-, del equívoco o del error de interpretación y la consiguiente situación humorística o ridícula que provoca, existen otras perspectivas para enfocar este tema, cosa que pocas veces se ha hecho, y, cuando se hizo, tan sólo de pasada.

Así, pretendemos demostrar que, por el hecho de que portugués y español son lenguas románicas etimológicamente provenientes del latín, el significado de la palabra original de la que provienen los pares enfrentados realmente se mantiene en las dos Revista Leitura V.2 no 56 - jul/dez 2015 - Número regular - Autor/a: José Alberto Miranda Poza - p. $133-152$. 
lenguas, si bien, a lo largo de la historia respectiva de cada una, ha especializado su sentido, lo ha generalizado o incluso, en una, o en ambas, ha aparecido algún otro término que ha hecho variar los sentidos originarios, siquiera ligeramente.

Estas consideraciones nos conducen, por un lado, a la necesidad de retomar algunos de los presupuestos que estableció Michel Bréal (1982) cuando creyó encontrar “dos leyes o principios que, a su juicio, le permitían clasificar los cambios semánticos que se dan en el ámbito de la palabra, analizar las causas que los producen y explicar las razones por las que aparecen o desaparecen las palabras: ley de especialización y ley de repartición” (SALVADOR, 1985, p.52).

\section{La dimensión del fenómeno: interdisciplinariedad}

La naturaleza que encierra el fenómeno atañe a la interferencia lingüística y se produce por la transferencia de cierto tipo de estructuras de la lengua materna a la lengua meta por parte del hablante, institucionalizado o no, lo que implicaría una visión diferente del contacto de lenguas, más allá de la clásica que proporcionó Weinrich (1974). En este sentido, el problema de los falsos cognados vendría a identificarse con la interlengua, estadio necesario en el proceso de aprendizaje de lenguas segundas por parte del aprendiente o del hablante que no conoce completamente la lengua meta. A propósito de la interlengua y con relación a las particularidades de estas dos lenguas enfrentadas, tal tipo de equívocos léxico-semánticos toma especial relevancia cuando se caracteriza el portuñol (GARCÍA CALVIÑO y FERREIRA MONTERO, 2012).

Esta particular concepción del hablante que, en la práctica, cuando se encuentra en proceso de aprendizaje de una segunda lengua o, simplemente, cuando se comunica a través de ella, identifica erróneamente, en todo o en parte, la forma y el sentido de una unidad léxica de su lengua materna con otra unidad léxica de la lengua meta, nos lleva a tener presentes también las relaciones que existen entre lenguaje y pensamiento y lenguaje y cognición.

Este hecho muestra, sin duda, que el fenómeno de los falsos amigos no sólo atañe a un problema de lingüística contrastiva -la diferencia de significados entre dos vocablos pertenecientes a dos lenguas enfrentadas-, sino que además, por su naturaleza intrínseca, se trata de un problema que tiene que ver también con la semántica y áreas afines, la pragmática, por lo que se refiere al uso contextualizado o al sentido. Pero, ese uso no sólo atiende a sentidos contextualizados, sino a variantes que dependen, más allá del contexto en su acepción estrictamente textual, de la dimensión espacial -eje Revista Leitura V.2 no 56 - jul/dez 2015 - Número regular - Autor/a: José Alberto Miranda Poza - p. $133-152$. 
diatópico- o de las características propias del hablante - eje diastrático- (MIRANDA POZA, 2007, p.34), con lo cual, hablamos también de sociolingüística.

Aún más, el hecho de que este proceso de identificación entre dos lenguas en contraste se produzca, en realidad, en la mente del hablante, nos lleva hasta la teoría lingüística y sus relaciones interdisciplinares, y hablamos, entonces, de la psicología cognitiva, o de forma más general, de los procesos cognitivos que acompañan a los lingüísticos. Por fin, el equívoco se fundamenta otras veces en el parecido formal de los términos enfrentados en el eje oral-escrito, lo que nos lleva a hablar de cuáles son las relaciones entre los sistemas fónicos y gráficos de cada una de las lenguas, y nos obliga a citar aquí, por un lado, la fonología -y sus correspondientes realizaciones: fonética-, y, por otro, las denominaciones referidas a la disciplina que estudia los sistemas gráficos en su relación con los sistemas fónicos: grafémica, grafética o grafemática (MIRANDA POZA y DA COSTA, 2008, p.198).

Tampoco huyen del problema que abordamos los aspectos históricos que explican el motivo por el cual se han producido casos de homonimia (MASIP, 2013) o cómo dos palabras pertenecientes a dos lenguas y que poseen un étimo común han desarrollado en el eje temporal sentidos diversos, con lo que de nuevo volvemos a la lingüística histórica.

No dejemos de reparar en los objetivos que perseguían los trabajos sobre esta materia. Así, por ejemplo, Francis y Durão (2009) trazan como objetivo prioritario la investigación de una de las facetas que atañen a los procesos de enseñanza-aprendizaje de lenguas: los diccionarios bilingües. Se abre un nuevo ámbito, también relacionado en parte con la semántica: la lexicografía. Y, para cerrar el círculo definitivamente, si hablamos de lexicografía, lo hacemos también de lexicología siguiendo la definición propuesta por Coseriu (1991): “cualquier estudio que sobre el léxico de una lengua pueda establecerse, tanto si se refiere al plano de la expresión, onomasiología, como al plano del contenido, semasiología” (MIRANDA POZA, 2011, p.8).

Por un lado, descubrimos que, considerado el lenguaje en su esencia, como atributo biológico de la especie humana: “qué es el lenguaje?” (ALONSO-CORTÉS, 1989), y no sólo en su utilidad práctica, desde perspectivas comunicativas e interaccionistas: “¿para qué sirve el lenguaje?”, “¿cómo funciona el lenguaje” (LEAL, 2010), el fenómeno de los falsos cognados tiene consecuencias fundamentales a la hora de explicar determinados hechos lingüísticos en las interfaces lengua vs usuario. El Revista Leitura V.2 no 56 - jul/dez 2015 - Número regular - Autor/a: José Alberto Miranda Poza - p. $133-152$. 
hablante piensa a partir de su lengua materna, y ese pensar le proporciona una consciencia sobre cómo interpreta la realidad circundante según la idiosincrasia estructural y formal, pero también cultural e ideológica- que subyace en su propia lengua. Estos procesos cognitivos pueden llegar a ser conscientes, si bien, el llamado conocimiento epistemológico no se da necesariamente en el hablante por el mero hecho de serlo (ALONSO-CORTÉS, 1989). Pues bien, en la atribución, recepción o concepción de las supuestas semejanzas entre los pares de vocablos considerados como amigos falsamente, este tipo de hecho, completamente subjetivo, posee también una naturaleza cognitiva.

Por otro lado, la asociación que el hablante establece se refiere mucho más al sentido de la forma que a su significado, es decir, se produce en todo acto de habla un inmediatismo pragmático teñido de todos los matices que pudieran caber: características diatópicas, lo que un término significa prioritariamente en una determina región, diastráticas, lo que un término significa para un hablante en tanto que forma parte de determinado grupo o grupos sociolingüísticos, y diafásicas, lo que un término significa de forma prioritaria cuando los interlocutores interaccionan en un contexto lingüístico específico, ya sea situacional o textual (género), esto es, hablamos a grandes rasgos de factores culturales e ideológicos. Si dentro de la propia lengua la existencia de estas variantes da lugar a equívocos, mucho mayores serán estos cuando se producen entre lenguas distintas y además próximas.

\section{Objetivos y alcance de nuestra propuesta de análisis}

Nuestro objetivo no puede ser tan sólo el de llamar la atención sobre este fenómeno, pues tiene tanta dispersión y ha sido tan tratado desde perspectivas diversas, aun en el caso de que los resultados divergentes puedan ser discutibles, que resultaría estéril repetir lo ya dicho hasta ahora.

No pretendemos mostrar dónde se producen falsos cognados en la interface español-portugués, tampoco cómo se analiza el problema en materiales didácticos al uso o en diccionarios, llegando en casi todos los casos a la misma conclusión: deficiencias en el tratamiento, debido a que siempre faltan algunos de los múltiples aspectos atinentes al problema. Creemos que no sólo es deseable detectar dónde se producen los equívocos, o determinar, a través de modernos procedimientos tecnológicos, cuáles son los más recurrentes, esto es, las parejas de falsos amigos con mayor frecuencia de apareción en los potenciales discursos de los aprendientes -en las dos direcciones, esto Revista Leitura V.2 no 56 - jul/dez 2015 - Número regular - Autor/a: José Alberto Miranda Poza - p. $133-152$. 
es, de quien aprende español desde su portugués nativo y viceversa-. Tiene su interés, sin duda, especialmente cuando se escribe para profesores, analizar los materiales más en boga y cómo en ellos se trata de un problema que resulta fundamental para la enseñanza del idioma, proponiendo nuevos materiales, abordajes y ejercicios. Pero, sería interesante, además, preguntarnos y encontrar un porqué a la existencia de estos fenómenos equívocos cuando se parte de un étimo común, y no sólo y exclusivamente en ese caso (MIRANDA POZA, 2012).

Un breve inciso a este respecto. Cuando hablamos de crear materiales y libros destinados al estudio y reflexión -a veces, se emplea el término "uso" en lugar de los dos anteriores- de los profesores y formadores, se insiste en que los temas tratados y el tipo de enfoque se caractericen por una inmediatez absoluta en relación con el ejercicio de la profesión en la clase. En este sentido, alineándonos con lo expuesto por Ramalho (2010), pensemos cuán lejos de nosotros se hallan concepciones utilitaristas de la universidad como las que describe Santos (2005, p.138-139): "La universidad debería ser sobre todo una prestadora de servicios a la sociedad y que tales servicios proporcionen algún beneficio económico". Este es, precisamente, uno de los peligros a que nos conduce una concepción mediatizada de la universidad y sobre los que llama la atención Pereira (2009, p.50), para quien la situación actual del saber con la sociedad instaura una nueva relación: la del saber como proveedor del usuario, consumidor. Se trata, pues, "de un saber-producto, una mercancía, una inversión, un proceso de disputa y valor comercial de la información, de la ciencia y de la tecnología, que genera la pérdida de valor del saber como formador del carácter, de la ética y del espíritu reflexivo". Lo dicho para la universidad vale en términos genéricos para la educación, que debe evitar la trampa de convertirse en un simple instrumento al servicio de fines inmediatos. No se trata de aprender habilidades para ganarse la vida, sino que la esencia de la educación va mucho más allá, al desarrollar una facultad para la que a veces y a priori no conocemos un uso concreto y directo.

Todo lo anterior no resulta trivial en la universidad actual, pues bajo el manto de una supuesta modernidad, embozada en los estudios de lingüística aplicada, se ha condenado al olvido a una de las perspectivas que proporciona la explicación de los hechos. Tal ideología educativa considerara la ausencia de objeto específico de todo enfoque de carácter histórico de los hechos lingüísticos, tal vez con la excepción de ciertos aspectos sociológicos. Y he aquí que, para el problema que estamos tratando, la Revista Leitura V.2 no 56 - jul/dez 2015 - Número regular - Autor/a: José Alberto Miranda Poza - p. $133-152$. 
visión histórica puede saciar la curiosidad intelectual que resulta esencial para un profesor, pues ofrece una visión panorámica de los hechos lingüísticos a lo largo de la historia de dos lenguas que, a partir del latín (a veces, del griego), nos permite asistir a la progresiva diversificación de lo que en origen fueron dos dialectos (hoy lenguas, español y portugués) de esa tronco originario.

No ha sido otra la metodología que desarrollamos en el ejemplo práctico de nuestro trabajo. En efecto, hemos seleccionado, a modo de propuesta, un par de falsos cognados y nos hemos preguntado por su étimo. Entonces, hemos descubierto las dos caras de la filología aplicada a la lexicología, pues no sólo hemos abordado la historia de la forma, sino que además nos hemos preocupado por ofrecer, de forma breve, la historia de los significados que en cada lengua, a lo largo de los siglos, ha seguido a la forma correspondiente, debido a factores diversos.

Estas interacciones históricas de portugués y español con relación al latín nos llevan también a relacionar tales fenómenos con la deriva que siguieron otras lenguas románicas: francés, catalán, gallego o italiano, según el caso. Perspectiva que nos conduce, a su vez, a tener en cuenta el hecho de que la palabra y aún la lengua no están aisladas. Queremos decir que estudiar pares de vocablos en los que se produce un fenómeno de falsos amigos de forma aislada no siempre explica el fenómeno en sí considerado en su totalidad. No se puede reducir, en ocasiones, el universo de la explicación del fenómeno a las lenguas enfrentadas, de manera que nos vemos abocados a mencionar también lo que ocurrió en otras lenguas románicas.

\section{Análisis del par: "suceso / sucesso"}

Tanto la palabra española suceso como la portuguesa sucesso provienen del sustantivo latino successus, $-\bar{u} s$, 'secuencia, sucesión', 'éxito` (COROMINAS y PASCUAL, 1983, V, p.12-13), derivado, a su vez, del participio pasivo successus, a, um, del verbo succēdo, is, ĕre, cessum. Este último verbo es también palabra derivada, proveniente de otro verbo, cēelerre, 'retirarse, marcharse', 'no resistir' (COROMINAS y PASCUAL, 1983, V, p.324). Con todo, al hacer referencia al vocablo portugués, Machado (1995, V, p.240) ofrece un sustancioso ejemplo del siglo XVI: "Em todas as obras humanas há bom e mau sucesso, culpa e louvor, glória e pena...”, donde parece claro el sentido neutro que encerraba la palabra, esto es, ni negativo, ni positivo. Blánquez Fraile (1978, p.478) aboga por la teoría de que ya en el propio latín la palabra successus, -ūs poseía un doble valor: a) 'aproximación, venida, llegada'; b) evento Revista Leitura V.2 no 56 - jul/dez 2015 - Número regular - Autor/a: José Alberto Miranda Poza - p. $133-152$. 
próspero, favorable`. Y, de hecho, Machado, a pesar del ejemplo aducido, así parece confirmarlo cuando, un poco antes, define sucesso como "acto de penetrar no interior de [...], aproximação, chegada, marcha para frente, resultado, triunfo" (MACHADO, 1995, V, p.240).

Ocurre, por otro lado, que, tanto en portugués como en español, se documenta la palabra éxito / éxito, y, además, con el mismo significado: 'resultado feliz de un negocio, actuación, etc. ‘; 'buena aceptación que tiene alguien o algo` (DRAE, 2001, p.690). Y el problema está en que en portugués conviven las formas sucesso y êxito con el mismo significado, siendo, al menos en Brasil, más común en el uso la primera. El conflicto entre las lenguas próximas se produce cuando en español suceso significa 'cosa que sucede, especialmente cuando es de alguna importancia' y además -sólo como cuarta y quita acepción respectivamente-, 'hecho delictivo', 'accidente desgraciado`(DRAE, 2001, p.1428). Considerando estas dos últimas acepciones del español suceso, por oposición a la acepción más actual de sucesso en portugués, cabe hablar del fenómeno de falsos amigos. Pero, no olvidemos la acepción más genérica del término, que es la primera que aparece en el DRAE, ni perdamos de vista el ejemplo del portugués del siglo XVI que ofrecía Machado. Y, para incidir en esta cuestión, el propio diccionario académico nos puede dar alguna sorpresa cuando leemos la tercera acepción que atribuye al término español: 'éxito, resultado, término de un negocio', con lo que los falsos cognados no serían tan falsos como pudiera parecer en un principio.

Porque estos últimos datos nos invitan a considerar que el poder de la etimología es mayor de lo que en principio pudiera parecer y mucho mayor que aquellos que rechazan, por innecesaria, la perspectiva histórica en los estudios lingüísticos actuales. Así, en español, según el diccionario lo atestigua, suceso también puede aplicarse, como en portugués, a un hecho positivo o feliz, si bien, no es lo más usual hoy en día, porque históricamente para ese significado de prosperidad se especializó otra palabra, éxito, que posee su particular historia.

La palabra éxito (también la forma portuguesa êxito) proviene del verbo latino exīre, derivado, a su vez, de ìre 'ir', de donde, exīre, que significaría literalmente 'ir hacia fuera, ir hacia delante` (COROMINAS y PASCUAL, 1983, II, p.824). De exīre se formó el verbo castellano antiguo exir, que aún existe en valenciano actualmente, así como sus derivados: exida (cast.ant.; val.) 'salida' y, por supuesto, éxito. También la palabra éxito poseyó un sentido genérico, ni positivo, ni negativo aún en el siglo XVIII, Revista Leitura V.2 no 56 - jul/dez 2015 - Número regular - Autor/a: José Alberto Miranda Poza - p. $133-152$. 
según documentan Corominas y Pascual (1983, III, p.462-463): "Moratín habla de un éxito infeliz", en el sentido de 'salida o resolución de algo', aunque ya en el Diccionario de Autoridades, en época contemporánea a la del citado autor, se dice de una empresa ardua que "no tendrá éxito" (con todo, entiéndase aquí como 'salida', en sentido abstracto; y sólo a partir de él, 'perspectivas o resultados favorables`). Precisamente este es el significado que recoge como acepción del término portugués êxito Machado (1995, II, p.514): 'acto de sair, saída; morte, fim; resultado; fim, termo`.

Obsérvese que, al definir éxito / êxito, han surgido las palabras salida / saída, que poseen su propia etimología. Estas últimas derivan del verbo latino sălĭo, is, ìre, sălŭi, saltum, cuyo significado era 'saltar, brincar, dar saltos` (BLÁNQUEZ FRAILE, 1978, p.437). Ya desde la época de orígenes, en el Mío Cid, se documenta el verbo salir con el sentido de 'pasar de dentro afuera', de donde su derivado salida, que se generaliza en castellano, dando lugar a la posterior desaparición en la lengua española de uno de los lexemas en conflicto, exida (COROMINAS y PASCUAL, 1983, V, p.139-140). Por su parte, y con relación al portugués, Machado (1995, V, p.142) documenta la parcial desaparición de exīre cuando redacta el artículo de la palabra sair: “do lat. salīre, 'saltar, pular, vibrar [...], sair', que, portanto, se encarregou de substituir parcialmente exīre".

Ahora bien, hemos mencionado a propósito de la definición del latín sălĭo, el verbo español brincar, con su sentido actual de 'dar saltos, dar brincos`. Pero, brinco, en portugués, no es un 'salto`. Es más, se da el caso de que el español brincar proviene del portugués brincar, cuyo significado era, y continúa siendo, 'jugar, retozar`. El vocablo portugués es un derivado del sustantivo brinco, 'anillo, sortija, juguete para los niños`, procedente, a su vez, del latín vincǔlum, $\bar{\imath}$ ’atadura, lazo, ligadura` (BLÁNQUEZ FRAILE, 1978, p.537). ${ }^{2}$ Relacionada con esta última etimología, se encuentra la palabra española vinco, que el DRAE (2001, p.1564) documenta como leonesismo, región vecina de Portugal, con dos acepciones: una en singular, 'anillo de alambre que se pone en el hocico a los cerdos para evitar que hocen`; y otra en plural, 'pendientes que usan

\footnotetext{
${ }^{2}$ Ou brincar provenha de springan, no sentido de 'pular', e de bli(n)kan, no de 'gracejar, entreter-se', sendo portanto formas convergentes; ou proceda de um só destes verbos germânicos, sendo a segunda acepção desenvolvimento da primeira; ou ainda, o substantivo brinco significando 'pingente` seja o latim uinc(u)lum, independente portanto de brinco: o que é certo é que este em português adquiriu significados em que o seu correspondente castelhano brincar, 'pular’, o não seguiu, pois se diz ali jugar, juguetear. Brinco: 'brinquedo'. Documentada no séc.XVI com o sentido de 'enfeite, ornamento' e mais concretamente 'enfeite de orelhas (MACHADO, 1995, I, p.465).

Revista Leitura V.2 no 56 - jul/dez 2015 - Número regular - Autor/a: José Alberto Miranda Poza - p. $133-152$.
} 
las mujeres formados por un aro de plata'. La forma española brinco con el sentido de 'saltar como los niños` puede deberse, según Corominas y Pascual (1983, I, p.655-656) a que el término se aplicó, a partir de 1589, a un aro u objeto semejante de forma anular, como los que rematan los chupetes de los niños de teta actualmente. De forma que en Cervantes, Lope de Vega y autores contemporáneos, ya se documenta brinco derivado de brincar como 'salto'.

Entonces, si brinco (brincar) es salto, saltar, a su vez, va perdiendo paulatinamente su sentido de 'joya'; por lo tanto, el español ha de buscar otra denominación, otra palabra, que signifique ese valor desviado o metafórico que adquirió la original que lo poseía: pendiente, del latín pendens, tis, participio de presente del verbo penděo, es, ère, pěpendi latino, que explica el origen del castellano pender < pĕndēre, 'suspendido, estar colgado de’ (BLÁNQUEZ FRAILE, 1978, p.348). En español, la forma pendiente, presenta dos valores: uno, como sustantivo, equivaldría al brinco del portugués, e incluso a una de las acepciones del leonesismo vinco; la otra, como adjetivo, presenta un significado derivado de su sentido original 'no resuelto', pero, con este valor, entra en conflicto con pendencia, palabra formalmente próxima no directamente relacionada con ella etimológicamente, pero con la que compartía significados fronterizos, de manera que, una vez establecido el conflicto, pendencia especializó su uso, en sentido negativo, primero manteniendo un cierto vínculo con el significado etimológico 'situación apurada, alarma', para definitivamente desembocar en el sentido actual 'riña, pelea` (COROMINAS y PASCUAL, 1983, IV, p.475-476). Porque pendencia no proviene de pěndère -étimo de pendiente-, sino de paenitentia 'pesar', derivada de paenitere 'arrepentirse', en portugués antiguo, arrepender-se.

De este modo, pendiente, como sustantivo, sólo existe en español con significado equivalente a brinco en portugués. El adjetivo pendiente (pendente, en portugués) posee el mismo significado en ambas lenguas, derivado del original, en el sentido de 'no concluido, no acabado o no resuelto`. A partir de este último, el español otorga al sustantivo pendiente el significado de 'cuesta o declive de un terreno` (DRAE, 2001: p.1720). La palabra pendencia en español restringió su significado a 'contienda, riña`, a partir del sentido etimológico derivado de paenitentia, 'arrepentimiento, disgusto`, mientras que el portugués especializa el significado de pendência como 'litígio`, al lado de otros valores semejantes 'briga, contenda`, valores todos ellos derivados de otro que entra en conflicto con pendente, por más que su etimología sea Revista Leitura V.2 no 56 - jul/dez 2015 - Número regular - Autor/a: José Alberto Miranda Poza - p. $133-152$. 
dispar: 'tempo durante o qual uma causa ou um recurso está pendente ou correndo` (FERREIRA, 1999, p.1534).

¿Qué fenómenos históricos se han producido realmente? Como anticipamos más arriba, hemos de volver a Bréal (1982) para referirnos a la ley de especialización y a la ley de repartición de significado. Antes, en un trabajo fundacional, el propio autor había hablado de una tercera, la ley de especialidad, que consiste en otorgar a una única palabra la función que con anterioridad era realizada por toda una serie de la misma especie. Por su parte, la ley de especialización defiende que términos que en la lengua común tienen un significado general tienden a ser empleados por cada grupo profesional, clase social, etc., con otro más específico que comporta la marca de aquello que los representa (MUÑOZ NÚÑEZ, 1999, p.48-49). Por último, la ley de repartición sostiene que "cada vez que se produce sinonimia en una lengua las voces implicadas en ella tienden a repartir su contenido y acaban por diferenciarse semánticamente" (SALVADOR, 1985, p.53).

Mediante estos conceptos vamos a conseguir explicar la compleja serie de procesos que se llevaron a cabo, en el sentido de que, lejos de lo que habitualmente se suele mostrar, la existencia de esos pares de supuestos falsos amigos no se da por un azar del lenguaje, ni mucho menos de forma aislada con relación a las dos lenguas enfrentadas en general o al resto de vocablos de cada una de ellas, en particular.

Partíamos inicialmente del par suceso / sucesso, palabras que comparten un mismo étimo, el sustantivo latino successus, derivado del verbo succedĕre, cuyo significado era 'aproximación, llegada', si bien se apunta, aún en época latina, un sentido próximo a 'favorable`. De forma paralela, reparamos en el par éxito (esp.) / êxito (port.), términos relacionados etimológicamente con exida, 'salida, fin, término', documentada en castellano antiguo y en valenciano actual, derivadas todas ellas del verbo latino exīre. Encontramos, además, documentación que nos informa de que, en época antigua, el portugués sucesso podía ser bom e mau (MACHADO, 1995, V, p.240) y el español éxito, podía ser infeliz (COROMINAS y PASCUAL, 1983, III, p.462-463). Nos encontramos con dos vocablos que poseen dos etimologías diferentes y que, originalmente en latín no presentaban el mismo significado, que en su evolución histórica fueron perfilando sus matices significativos, llegando a colisionar en época romance. Entonces, aplicando las tesis de Bréal (1982), podemos decir que, por un lado, para mantener la oposición preexistente y, al mismo tiempo, para evitar un fenómeno de Revista Leitura V.2 no 56 - jul/dez 2015 - Número regular - Autor/a: José Alberto Miranda Poza - p. $133-152$. 
sinonimia, se produjo a través de su realización, en el uso, una reorganización. ${ }^{3}$ Ocurrió que en las respectivas comunidades en que se hablaba cada lengua se produjeron reacciones dispares, lo que explica la situación actual. Así, en español, una vez que se llegó a una situación de sinonimia, se produjo una repartición de significado, esto es, suceso se vinculó esencialmente al significado de hecho delictivo', 'accidente desgraciado` (DRAE, 2001, p.1428), por oposición a éxito: 'resultado feliz de un negocio, actuación, etc.`; 'buena aceptación que tiene alguien o algo` (DRAE, 2010, p.690). Por el contrario, en portugués, una vez que se llegó a la situación de conflicto, se mantuvo la sinonimia, pero, el habla suele privilegiar como más usual la forma sucesso, en detrimento de êxito. Ahora bien, tanto la repartición de significado en español como en la tendencia a privilegiar en el uso de una de las formas en portugués, se producen una vez que se ha dado una especialización en el significado adquirido. Así, se documenta tanto la posibilidad de asociar una valoración alternativa opuesta, positiva y negativa, al término sucesso en el portugués del siglo XVI, como al término éxito en el español del siglo XVIII.

Ahora bien, ¿por qué éxito / êxito se impregnan de nuevos matices de sentido, que los lleva a alejarse del significado originario y a crear la situación de conflicto con suceso / sucesso, llegando a provocar, incluso, la desaparición del verbo del castellano antiguo exir < lat. exīre? Para explicar este fenómeno, debemos observar lo que ocurrió con el verbo que vino a sustituir semánticamente al desaparecido exir < lat. exīre: salir / sair. Tanto el verbo salir / sair como sus derivados salida / saída provienen del verbo latino salīre que, en principio, significaba 'saltar, brincar', de donde se explica, con este mismo valor, el español salto, derivado del participio pasado saltum, del mismo verbo salīre, pero que, a su vez, en salida (cf. port. saída), comenzó a adquirir el significado de 'lugar por el que se pasa de dentro afuera`. No obstante, a pesar de este desplazamiento de significado, portugués y español mantienen aún términos provenientes de salīre que responden al significado etimológico original. Así ocurre con el verbo portugués salientar, literalmente, 'poner en alto', esto es, 'destacar, llamar la atención sobre`, y con los vocablos españoles sobresalir y su derivado sobresaliente, literalmente 'exceder en altura', después usado en sentido figurado. Pues bien, el

\footnotetext{
3 "Todas las palabras que debieran ser sinónimas y que incluso lo han sido momentáneamente en el pasado, han adquirido significados diferentes y han dejado de ser intercambiables. La sinonimia sería, pues, un accidente una coincidencia pasajera a la que la lengua pone enseguida remedio" (SALVADOR, 1985, p.53).

Revista Leitura V.2 no 56 - jul/dez 2015 - Número regular - Autor/a: José Alberto Miranda Poza - p. $133-152$.
} 
desplazamiento de significado producido en salir < lat. salìre y sus derivados en dirección a lo que originalmente significaba exir < lat. exīre y sus derivados, fue lo que condujo a que formas romances como éxito / êxito se contagiasen de nuevos valores, que, a su vez, entraron en conflicto con los que originariamente poseían otras palabras, como suceso / sucesso. ${ }^{4}$

Una vez que salir ha adquirido un nuevo significado, 'dirigirse a un lugar de dentro afuera`, el significado etimológico 'dar saltos`, debe recaer en una nueva forma. En español, se ofrecen dos posibilidades: a) recuperar un verbo poco frecuente en latín clásico, alternativo de salı̆o, saltar, proveniente de salto, as, āre, āvi, àtum, que realmente significaba en época clásica 'bailar, danzar con gestos y pantomimas’, es decir, hacer otro tipo específico de saltos (BLÁNQUEZ FRAILE, 1978, p.437); b) paralelamente, acrecentar el acervo léxico a través de la apropiación, préstamo léxico, de la forma brincar, que el portugués adoptó y cuyo origen al parecer es germánico, si bien no se descarta un cruce etimológico entre springan, en el sentido de 'saltar', y de bli(n)kan 'jugar` con el vocablo latino uinc(u)lum; y, entonces, en portugués, primero fue brinco 'juguete` y después llegó brincar cuyo significado, en cualquier caso, era 'jugar, retozar', valor con el que permanece en esta lengua hasta hoy, pero que en español se traslada a la casilla vacía de significado que había dejada sin cubrir perfectamente el verbo salir cuando en castellano adoptó el nuevo sentido de exīre, olvidando el que poseía en latín salīre, entendiéndose como un tipo de juego o retozo específico consistente en 'dar saltos', significado que se comparte con el nuevo valor adoptado para el verbo saltar. ${ }^{5}$ Con todo, hoy en español, saltar y brincar no son

\footnotetext{
${ }^{4}$ Véase la solución que ofrecieron otras lenguas románicas, en especial, las del grupo galorrománico. Así, en lugar de adoptar derivados del verbo latino salīre para recubrir el significado de exīre (fr.ant. issir), se recurrió a un verbo sortir y sus respectivos derivados, sortida (cat.), sortie (fr.). La etimología de sortir es oscura (ROBERT, 1977, p.1837-1838). Se sugiere, de un lado, la alteración del latín clásico surrectus en la forma vulgar *surctus, participio del verbo surgo, is ěre, surrexi, surrectum, 'poner en pie, erigir, levantar` (BLÁNQUEZ FRAILE, 1978, p.485), a la que se asociaría el nuevo sentido. De otro, mucho más probable que la tesis anterior, se relaciona sortir con el verbo latino sortǐor, ìris, ìri, ìtus sum 'sacar la suerte, echar la suerte', derivado, a su vez, del sustantivo sors, sortis 'todo objeto que se ponía en una urna o cajita para sacar a suerte (BLÁNQUEZ FRAILE, 1978, p.463).

${ }^{5}$ Ello no quiere decir que, necesariamente, la estructuración que el léxico de cada lengua va adoptando a lo largo de su evolución histórica haya de cubrir todos los espacios de significado a través de lexemas específicos. Ni siquiera que, en una determinada época, el léxico de una lengua dada haya de cubrir biunívocamente los diferentes significados (SALVADOR, 1985). Coseriu (1977) desdice la sugerencia que, en este sentido, parecía realizar Trier (1931) cuando definió el campo semántico como un "conjunto de palabras no emparentadas etimológicamente en su mayor parte (ni tampoco unidas entre sí por asociaciones psicológicas, individuales, arbitrarias, contingentes) que, colocadas una al lado de otra como las piedras irregulares de un mosaico, recubren exactamente todo un terreno bien delimitado de Revista Leitura V.2 no 56 - jul/dez 2015 - Número regular - Autor/a: José Alberto Miranda Poza - p. $133-152$.
} 
exactamente sinónimos, sino que, parafraseando a Bréal (1982), han repartido su significado, especializándolo a la vez. En efecto, saltar hoy en español es 'salvar de un salto un espacio o distancia' (DRAE, 2001, p.2015), mientras que brincar significa 'dar brincos o saltos' (DRAE, 2001, p.356). Se entiende, por tanto, que un brinco es un tipo de salto, 'súbito, leve', pero que no todos los saltos son brincos, luego brincar es saltar, pero no siempre que se salta se brinca.

Pero, brinco en portugués no significa 'salto', sino que hace referencia a un tipo de joya o adorno que se coloca en el lóbulo de la oreja. Un nuevo par de falsos cognados que, por la historia del término, nos empuja a pensar que el español lo tomó prestado del portugués. Al igual que el español, tomó en préstamo el verbo brincar como solución parcial para cubrir el significado etimológico que poseía salir, una vez que había desplazado su significado, de nuevo se vio obligado a recurrir a otro término, que no va a compartir con el portugués, toda vez que este idioma, con relación a la palabra brinco, se limitó a precisar o especificar su significado original, como ya explicamos: de 'juego, juego de niños` pasó a designar un tipo de juguete en forma de aro que estos utilizaban para jugar, de donde, en virtud de su forma, se aplicó también a una argolla de tipo circular que se utilizaba como ornamento habitualmente en la oreja. Entra entonces en juego la forma pendiente, que en principio, igual que en portugués (pendente) era el participio presente del verbo pender < lat. pĕndēre y que funcionaba como adjetivo, con el sentido de 'que cuelga, que pende de, que está suspenso`. De ahí, por semejanza, se metaforiza el sentido y se aplica a la joya u ornamento que pendía de donde se fijaba, surgiendo así el sustantivo pendiente, equivalente significativamente a brinco (portugués) y también, por otro lado, pendiente significa en español 'cuesta o declive de un terreno`(DRAE, 2001, p.1720).

Por último, considerando enfrentados los adjetivos pendiente / pendente, entra en discusión otro par: pendencia / pendência. La palabra pendencia en español restringió su significado a 'contienda, riña`a partir del sentido etimológico derivado de paenitentia, 'arrepentimiento, disgusto`, mientras que el portugués especializa el significado de pendência como 'litígio`, al lado de sentidos semejantes 'briga, contenda', valores todos ellos derivados de otro que entra en conflicto con pendente

significaciones, constituido, ora tradicionalmente, ora científicamente, por la experiencia humana" (apud MIRANDA POZA, 2011, p.92).

Revista Leitura V.2 no 56 - jul/dez 2015 - Número regular - Autor/a: José Alberto Miranda Poza - p. $133-152$. 
'não concluso`, por más que su etimología sea dispar: 'tempo durante o qual uma causa ou um recurso está pendente ou correndo` (FERREIRA, 1999, p.1534). ${ }^{6}$

\section{Consideraciones finales}

Hemos abordado en las páginas precedentes un problema que ha sido tratado profusamente y desde otras perspectivas cuando se analizan las relaciones entre el portugués y el español en el ámbito del vocabulario, y muy en especial, con relación a los problemas de enseñanza-aprendizaje de lenguas extranjeras, al desarrollo de la interlengua en el aprendiente, así como a cuestiones atinentes a la interferencia lingüística en general.

Las metodologías y las estrategias que el profesor de lengua extranjera debe desarrollar en el ejercicio de su actividad docente tienden a fomentar en los últimos tiempos las cuestiones más relacionadas con la comunicación y la interacción, de carácter pragmático e inmediatista, con lo que se produce una tendencia a olvidar, e incluso rechazar, no sólo cuestiones gramaticales sino aún más, si cabe, las referencias históricas.

Sin duda, en función de las necesidades específicas del profesor en el aula derivadas del tipo de aprendiente y de enseñanza que cada circunstancia exija, las metodologías y estrategias en boga pueden ser válidas, pero cuando hablamos de formación de profesores a nivel universitario, esto es, de formación de futuros formadores, no podemos dejarnos llevar por el inmediatismo o el pragmatismo, o lo que es lo mismo, dicho en otros términos, por la comodidad o el simplismo. Porque una cosa es enseñar una lengua, extranjera o no, a alguien que la quiere aprender y otra muy distinta enseñar a ser profesor de esa lengua. En este sentido, un profesor debe ir más allá de lo meramente aparente y no sólo contentarse con la contemplación de su dinámica activa en el uso interactivo que proporciona la comunicación hodierna.

Los fenómenos equívocos a los que abocan, en la interacción comunicativa, los falsos cognados, muy en especial en lenguas tan próximas como español y portugués, tienen su porqué, su explicación, que va mucho más allá de la mera anécdota a la que conduce el propio equívoco y se deben a factores que sólo se explican desde el conocimiento de la historia de la lengua y que remontan a las lenguas clásicas y aún a otras -ya sea, según cada caso, el árabe o las lenguas indígenas de la América

\footnotetext{
${ }^{6}$ Para una visión panorámica del conjunto de fenómenos esbozados, pueden consultarse los esquemas que aparecen en los anexos del presente trabajo.

Revista Leitura V.2 no 56 - jul/dez 2015 - Número regular - Autor/a: José Alberto Miranda Poza - p. $133-152$.
} 
hispánica- que, en el curso de la historia, por diferentes motivos, entraron en contacto con las lenguas en cuestión y provocaron la reorganización de los sistemas lingüísticos y de los respectivos valores que asignaban a los vocablos, antiguos e importados.

\section{Referencias}

ALONSO-CORTÉS, Ángel Algunos supuestos fundamentales de la teoría lingüística. In: Lecturas de Lingüística. Madrid: Cátedra, 1989, p.13-30.

BEATO, Ana Paula M.; DURÃO, Adja Balbino A. B. A influência da língua materna na aprendizagem do léxico de uma segunda língua. Entretextos. Revista da PósGraduação em Letras: Estudos da Linguagem, 2, p.23-36. 2001.

BREAL, Michel. Essai de Sémantique (Sicence des significations). Saint-Pierre de Salerne, Brionne: Gérard Monfort Editeur, 1982.

BUGUEÑO MIRANDA, Félix Valentín. Sobre algunos tipos de falsos cognados. Anuario Brasileño de Estudios Hispánicos, VIII, p.21-27, 1998.

CAMORLINGA ALCARAZ, Rafael. Do português ao espanhol: os prós e os contras da proximidade. In: SEDYCIAS, João (org.) O ensino do espanhol no Brasil: passado, presente, futuro. São Paulo: Parábola, 2005, p.195-205.

COROMINAS, Joan; PASCUAL, José Antonio. Diccionario Crítico Etimológico Castellano e Hispánico. Madrid: Gredos, 1983.

COSERIU, Eugenio Principios de semántica estructural. 2a ed. Madrid: Gredos, 1991. DURÃO, Adja Balbino de Amorim Barbieri. Lenguas parecidas, no obstante, diferentes. El estado de la cuestión de los estudios de español en Brasil. In: FIAPE. I Congreso Internacional: El español, lengua del futuro. Toledo. s.p., 2005 [publicación electrónica]. Disponible en: http://www.mecd.gob.es/dctm/redele/MaterialRedEle/Numeros\%20Especiales/2005_ESP_05_ActasFIAPE/Ponencias/2005_ESP_05_ 02Adja.pdf?documentId=0901e72b80e4ce16 [Último acceso: 09/05/2016]

FEIJÓO HOYOS, Balbina L.; HOYOS ANDRADE, Rafael E. Dicionário de falsos amigos do espanhol e do português. São Paulo: Embajada de España / Consejería de Educación / Scritta Editorial, 1992.

FERREIRA, Aurélio B. de H. Novo Aurélio Século XXI: O dicionário da língua portuguesa. $3^{\text {a }}$ Ed. totalmente revista e ampliada. Rio de Janeiro: Nova Fronteira, 1999. FRANCIS, Maria Girata; DURÃO, Adja Balbino A. B. Uma reflexão sobre o tratamento dado a falsos amigos do par de línguas português-espanhol em dicionários Revista Leitura V.2 no 56 - jul/dez 2015 - Número regular - Autor/a: José Alberto Miranda Poza - p. $133-152$. 
bilíngues gerais e em dicionários de falsos amigos. In: DURÃO, Adja Balbino A. B. (org) Por uma lexicografia bilíngue contrastiva. Londrina: Universidade Estadual de Londina / Serviço de Publicações, 2009, p.79-97.

GARCÍA CALVIÑO, Juan M.; FERREIRA MONTERO, Hélder J. Dudas y obstáculos en el aprendizaje de ELE: El léxico. Brasília, DF: Consejería de Educación de la Embajada de España, Secretaría General Técnica, 2012.

KOESSLER, Maxime; DEROCQUIGNY, Jules. Les faux amis ou Les trahisons Du vocabulaire anglais (conseils aux traductuers). Paris : Librairie Vuibert, 1928.

LADO, Robert Lingüística contrastiva. Madrid: Ediciones Alcalá, 1973.

LEAL, Virginia. Introdução à Linguística. In: LUCIANO, Dilma T. y PIRES, Carolina L. (orgs.) Dimensão transdisciplinar na formação do professor. Recife: Editora Universitária da UFPE, 2010, p.85-147.

LEIVA, Myriam Jeannette S. Falsos cognatos em português e espanhol. Dissertação (Mestrado em Linguística). Orientadora: Eunice Ribeiro Henriques. Campinas: Instituto de Estudos da Linguagem / Universidade Estadual de Campinas, 1994. Disponible en: file://C:/Users/ibyte/Downloads/LeivaMyriamJeannetteSerey.pdf [Última consulta: 09/05/2016]

MACHADO, José Pedro. Dicionário Etimológico da Língua Portuguesa. (Com a mais antiga documentação escrita e conhecida de muitos dos vocábulos estudados). $7^{\mathrm{a}}$ ed. Lisboa: Livros Horizonte, 1995.

MASIP, Vicente. Armadilhas da língua espanhola: um guia completo. Recife: Editora Universitária da UFPE, 2013.

MIRANDA POZA, José Alberto. La universidad ante los desafíos de la enseñanza de español en Brasil. Eutomia. Revista de Literatura e Linguística, Recife, 10 (1) p.147$169,2012$.

Língua Espanhola II. Lexicologia. Recife: Editora Universitária da UFPE, 2011.

A propósito de los términos Español de España y Español de América. La expansión externa del español en América. Los testimonios de los Cronistas de Indias. In: España y América. Tres ensayos de lengua y literatura. Recife: Bagaço, 2007, p.2996.

MIRANDA POZA, José Alberto; DA COSTA, Zaine G. Problemas de confusión terminológica en la clase de E/LE. Sobre sonidos, fonemas y letras. In: MIRANDA POZA, José Alberto; RODRIGUES, Juan P.M.; CENTURIÓN, Juan Ignacio J. (orgs.) Revista Leitura V.2 no 56 - jul/dez 2015 - Número regular - Autor/a: José Alberto Miranda Poza - p. $133-152$. 
Anais do I Congresso Nordestino de Espanhol. Recife: Editora Universitária da UFPE, 2008, p.192-229.

MUÑOZ NÚÑEZ, María Dolores. La polisemia léxica. Cádiz: Universidad de Cádiz, Servicio de Publicaciones, 1999.

PEREIRA, Elisabete M. A. A universidade da modernidade nos tempos atuais. Avaliação, 14 (1), p.29-52, 2009.

RAMALHO, Marcelo B. El papel de las universidades brasileñas en la formación de profesores de español como lengua extranjera. Tesis Doctoral dirigida por la $\operatorname{Prof}^{\mathrm{a}} \operatorname{Dr}^{\mathrm{a}}$ Emma Martinell.Barcelona: Universitat de Barcelona, 2010.

REAL ACADEMIA ESPAÑOLA. Diccionario de la lengua española. $22^{\mathrm{a}}$ ed. Madrid: Espasa-Calpe, 2001.

ROBERT, Paul. Le petit Robert. Dictionnaire alfabetique et analogique de la langue française. Rédaction dirigée par Alain Rey et Josette Rey-Debove. Paris: Société du Nouveau Littré, 1977.

SABINO, Marilei A. Falsos cognatos, falsos amigos ou cognatos enganosos? Desfazendo a confusão teórica através da prática. Alfa, São Paulo, 50.2, p.251-263, 2006.

SALVADOR, Gregorio. Semántica y lexicología del español. Estudios y lecciones. Madrid: Paraninfo, 1985.

SCHMITZ, John Robert. A problemática dos dicionários bilíngües. In: OLIVEIRA, Ana Maria P.P.; ISQUERDO, Aparecida N. (org.) As ciências do léxico: lexicologia, lexicografia, terminologia. $2^{\mathrm{a}}$ ed. Campo Grande, MS: Editora da UFMS, 2001, p.16170.

TRIER, Jost. Der Deutsche Wordschatz in Sinnberzirk des Verstandes. Die Gesichte eine Sprachilchen Feldes. Heildelberg: C. Winter, 1931.

WEINRICH, Uriel. Languages in contact. Findings and Problems. Paris: Mouton, 1974.

WERNER, Reinhold. El diccionario bilingüe y la enseñanza del español como lengua extranjera. SIGNUM: Estudos Linguísticos, 9.1, pp. 205-38, 2006.

Algunos elementos de una teoría del diccionario bilingüe. Cicle de conferències 95-96. Lèxic, corpus i diccionaris. Barcelona: Institut Universitari de Lingüística Aplicada / Universitat Pompeu Fabra, 1997, p.113-131.

Revista Leitura V.2 no 56 - jul/dez 2015 - Número regular - Autor/a: José Alberto Miranda Poza - p. 133 - 152. 

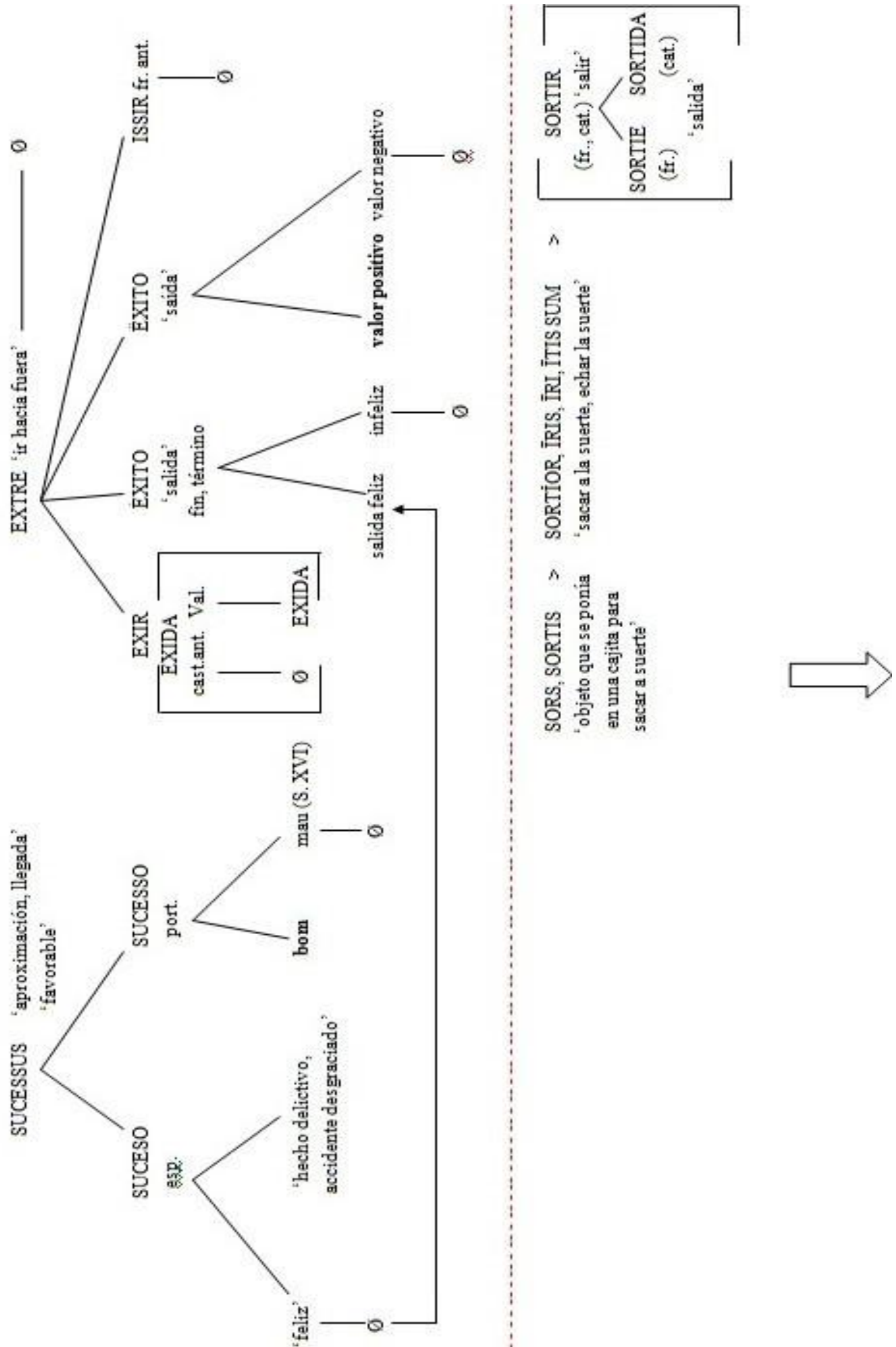

Revista Leitura V.2 no 56 - jul/dez 2015 - Número regular - Autor/a: José Alberto Miranda Poza - p. $133-152$. 


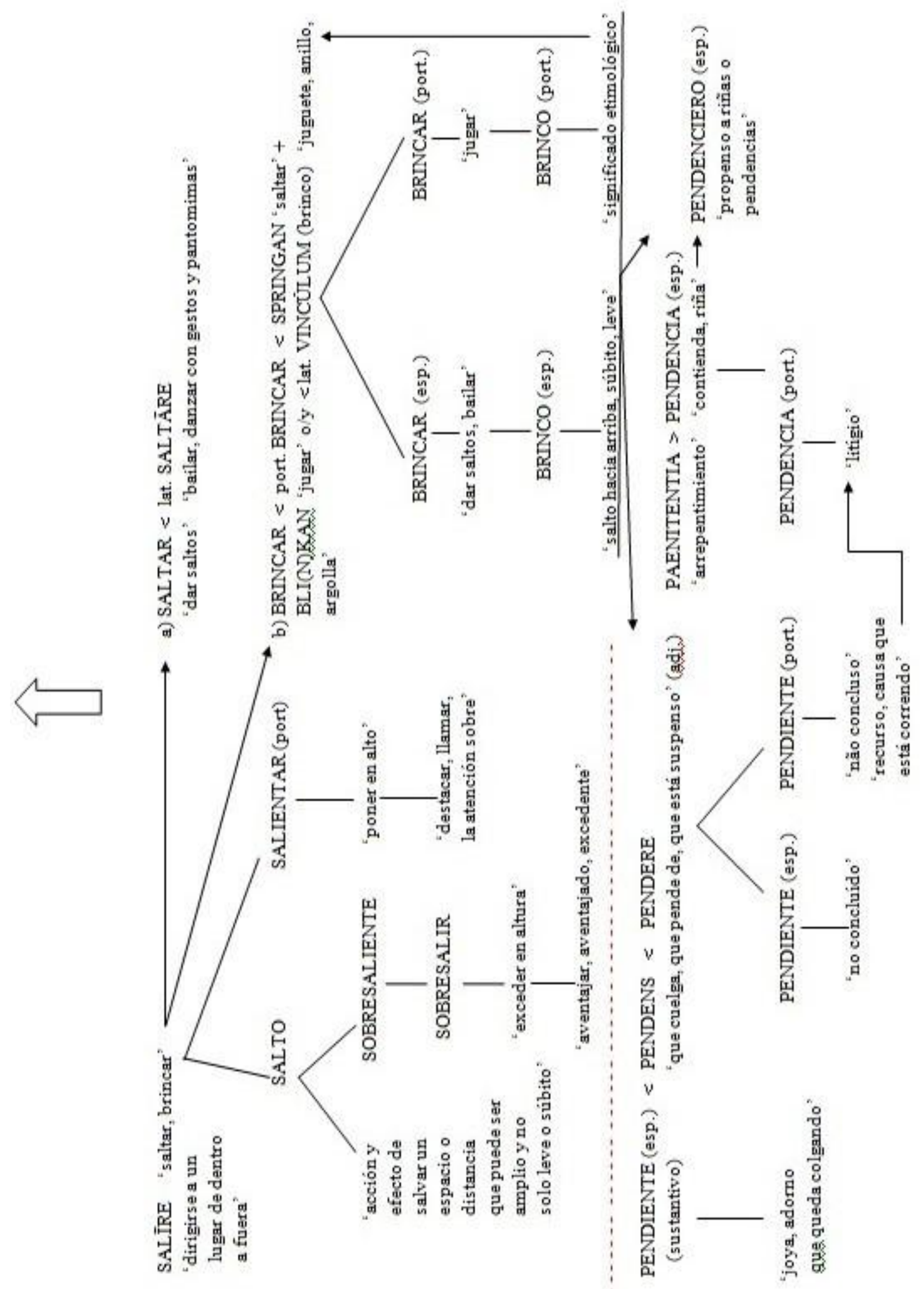

